\title{
A Study of “Chinese Cultural Aphasia” in Senior High School English Teaching
}

\author{
LIU Zhen-jie, JIN Ming-hao (Corresponding Author) \\ Yanbian University, Yanji, Jilin Province, China
}

\begin{abstract}
Based on collecting and analyzing the former studies, through the questionnaire, test paper and interview, this paper makes an investigation about Chinese Cultural Aphasia, which aims at finding out whether it exists or not and the reasons that are responsible for the phenomenon. The result shows: (1) “Chinese Cultural Aphasia” phenomenon does exist in Senior High English teaching, and students’ ability of expressing Chinese culture in English is worse than expected. (2) The reasons that are responsible for the phenomenon are in the following: Both students and teachers lack Chinese cultural consciousness, including that teachers' teaching idea is not correct and teaching method is single. What's more, in textbooks the proportion of Chinese culture content is too little. Accordingly, some proposals are put forward to solve the problem: (1) Students should pay attention to English expressions of Chinese culture. (2) Teachers should develop double culture ability, change attitude to English teaching, change the teaching method, use the textbooks neatly, increase the check of expressions related to Chinese culture. (3) Increase the proportion of Chinese culture in the textbooks.
\end{abstract}

Keywords: Chinese Cultural Aphasia, Senior High School, English teaching

\section{Introduction}

With the development of globalization, English has become an international language that is widely used all over the world. International communication becomes more and more frequent. Since China's reform and opening up, Chinese people have great interest in learning English, and English has become a compulsory course for Chinese students since primary school. But foreign language teaching in our country pays more attention to the teaching of foreign culture while neglecting the teaching of native culture, which caused students' disability to express their own culture in English exactly to foreigners, and this phenomenon is called "Chinese Cultural Aphasia” which is firstly put forward by Professor Cong Cong (2000) in Guangming Daily.

The study of "Chinese cultural aphasia” phenomenon in Senior High School is helpful to draw teachers' attention so as to promote the proportion of Chinese culture teaching in English course and arise students' enthusiasm to learn English. What's more, it also helps to cultivate students' cultural awareness and cultural personality. China is one of the four ancient civilizations, having long history and rich cultural heritage. It's necessary to strengthen the learning of Chinese traditional culture and learn how to introduce and spread our

LIU Zhen-jie (First Author), Postgraduate student for Master Degree, Department of English, Yanbian University. JIN Ming-hao (Corresponding Author), Ph.D., Associate Professor, Department of English, Yanbian University. 
brilliant native culture correctly in English, which can promote Chinese cultural identity toward glorious traditional culture.

\section{Theoretical Background}

\section{Definition of "Chinese Cultural Aphasia”}

"Aphasia" comes from the Greek word "aphatos". It means "speechless" and is first mentioned in neurolinguistics. The concept of aphasia is firstly used as the disease in medical science. According to National Aphasia Association, "aphasia" is defined as "a neurological impairment or disturbances of cortical tissue in the brain and results in reduced ability to read, write, speak and comprehend language.” In China, Professor Cong Cong (2000) of Nanjing University first cited the term "Chinese Cultural Aphasia.” According to him, it means that students are not able to express Chinese culture in English in cross-cultural communication.

\section{Empirical Studies on "Chinese Cultural Aphasia”}

After Cong Cong's statement of "Chinese Cultural Aphasia” phenomenon, many scholars have paid attention to the importance of balancing the culture teaching of target language and native language. And studies related to Chinese culture's education in foreign language teaching become more and more.

Yan Yilun (2002) highlighted the importance of learning one’s native culture in her paper, but she didn't illustrate some practical ways to solve the problem of “Chinese Cultural Aphasia” phenomenon.

Zhang Weimin and Zhu Hongmei (2002) conducted a research to non-English major students studing at Tsinghua University, using tests and interviews to analyze their capabilities of translating Chinese typical food, folklore, names of historical monuments and proportion of Chinese culture in English classroom teaching.

Liu Changjiang (2003) put forward three important processes to deal with the integration of target culture and native culture: the teaching syllabus, textbook compiling, and classroom teaching. Although he pointed out some suggestions, it was not suitable to senior high school students, because the teaching system of high school and colleges is different.

Xing Lisha and Wei Yaozhang (2012) discussed the cultural aphasia phenomenon of English Teaching in senior high school, and put porward some effective strategies to lead in Chinese culture in English teaching, at the same time, they illustrate the necessity in intercultural communication.

Zhao Hua (2017) conducted an investigation of "Chinese Cultural Aphasia" in a senior high school of Shi Jiazhuang, in which test papers and a questionaire are used to find out whether "Chinese Cultureal Aphasia" exists in senior high school as well as teachers' and students' attitude toward Chinese culture. The result shows that it does exist, and both teachers and students think it necessary to integrate Chinese culture to English teaching.

\section{Research Design}

\section{Research Questions}

There are three research questions in this paper. They are:

(1) Does Chinese Cultural Aphasia exist among Senior High School students?

(2) What factors cause this phenomenon?

(3) What solutions can be adopted to solve the problem? 


\section{Data Collection and Analysis}

The research is conducted in Wang Qing No.4 Senior High School of Yanbian Korean Autonomous Prefecture. 82 senior high school students and 5 teachers are investigated. The investigation is composed of three parts: (1) a questionnaire; (2) a test paper designed for students; (3) an interview for teachers, as shown in Table 1.

Table 1

Components of Questionnaire, Test paper and Interview

\begin{tabular}{lll}
\hline Types & Components & Number \\
\hline Questionnaires for student subjects & Multiple choices & 12 \\
Test paper for student subjects & Phrase & 10 \\
Interview for teacher subjects & Questions & 9 \\
\hline
\end{tabular}

The questionnaire is modified referring to Zhang Liyue's paper of Chinese Culture's "Aphasia" phenomenon in Middle School's English Teaching. And it is made up of twelve questions in order to find out whether the Chinese Cultural Aphasia exists or not and the possible reasons that are responsible for this phenomenon from the perspective of students.

The test paper is composed of ten phrases which cover the main aspects of Chinese culture, including literature, food, custom, art, entertainment and politics. Students are asked to express them in English, if necessary they can explain in their own words. The tested phrases are all typical ones that can represent Chinese culture from the ancient to the modern China and are connected with people's daily life.

The purpose of the interview is to find out whether senior high school teachers are aware of the imbalance in the teaching of native culture and target culture as well as their attitude to culture teaching. Each teacher is interviewed for 15 minutes, and the direct interview is used. There are nine questions in all.

The questionnaire lasts about 10 minutes and the test paper lasts about 20 minutes. 82 questionnaires and 82 test papers are given out, and all are effective.

\section{Results and Discussion}

\section{Questionnaire}

Table 2

Data Collection of Students' Questionnaires

\begin{tabular}{|c|c|c|c|c|c|c|}
\hline \multirow{2}{*}{ Question Items } & \multicolumn{2}{|c|}{ A } & \multicolumn{2}{|c|}{$\mathrm{B}$} & \multicolumn{2}{|c|}{$\mathrm{C}$} \\
\hline & Number & Percentage & Number & Percentage & Number & Percentage \\
\hline 1 & 16 & $19.5 \%$ & 60 & $73.2 \%$ & 6 & $7.3 \%$ \\
\hline 2 & 1 & $1.2 \%$ & 7 & $8.5 \%$ & 74 & $90.2 \%$ \\
\hline 3 & 7 & $8.5 \%$ & 13 & $15.9 \%$ & 62 & $75.6 \%$ \\
\hline 4 & 57 & $69.5 \%$ & 21 & $25.6 \%$ & 4 & $4.9 \%$ \\
\hline 5 & 2 & $2.4 \%$ & 25 & $30.5 \%$ & 55 & $67.1 \%$ \\
\hline 6 & 21 & $25.6 \%$ & 56 & $68.3 \%$ & 5 & $6.1 \%$ \\
\hline 7 & 44 & $53.7 \%$ & 34 & $41.5 \%$ & 4 & $4.9 \%$ \\
\hline 8 & 1 & $1.2 \%$ & 26 & $31.7 \%$ & 55 & $67.1 \%$ \\
\hline 9 & 12 & $14.6 \%$ & 57 & $69.5 \%$ & 13 & $15.9 \%$ \\
\hline
\end{tabular}


(table 2 continued)

\begin{tabular}{|c|c|c|c|c|c|c|}
\hline \multirow{2}{*}{ Question Items } & \multicolumn{2}{|c|}{ A } & \multicolumn{2}{|c|}{$\mathrm{B}$} & \multicolumn{2}{|c|}{$\mathrm{C}$} \\
\hline & Number & Percentage & Number & Percentage & Number & Percentage \\
\hline 10 & 18 & $22.0 \%$ & 60 & $73.2 \%$ & 4 & $4.9 \%$ \\
\hline 11 & 19 & $23.2 \%$ & 56 & $68.3 \%$ & 7 & $8.5 \%$ \\
\hline 12 & 3 & $3.7 \%$ & 50 & $61.0 \%$ & 29 & $35.4 \%$ \\
\hline
\end{tabular}

It is obvious that about $73.2 \%$ senior high school students think it difficult to express Chinese culture in English, and 67.1\% students can only receive information passively when communicating with foreigners. In terms of senior high school English textbook, most students think the proportion of Chinese culture content is too little. What's more, $69.5 \%$ students said that teachers often teach western culture and sometimes introduce Chinese culture only a few. Though most students know the importance of Chinese culture in English learning, they don't take any actions to improve the ability.

\section{Test Paper}

Although the Chinese Cultural Aphasia has been expected to exist among high school students, the result of the test is worse than expected. Most students can’t completely answer the questions. Some students even don't know how to express “孔子”, which use the expression of “Mr. Kong” or “kong zi”. For them, 《红楼梦》 is very difficult to explain, and most of them explained it as "a dream of red building”. Only 20 students know "Chinese Knot”, but most students can explain “压岁钱” well, such as lucky money, New Year’s Money or the money children get from parents in New Year. As one of the most popular food, “火锅” was explained so terribly that only 7 students get the right answer. It can be seen that senior high school students ignore the learning of culture expressions in daily life, even the most common phrases they don't know how to express in English. It is known that not only the phenomenon of Chinese Cultural Aphasia exists, but also it's very serious to some extent.

\section{Interview}

Among five interviewed teachers, two of them thought the ultimate goal of senior high school English teaching is for the purpose of NEMT, and three teachers thought it's for the development of students and apply it in the future. They all think that students' ability of expressing Chinese culture in English is very poor, and in the textbooks the proportion of Chinese culture is very little. They have realized that it is very necessary to add Chinese culture to senior high English teaching, and some of them sometimes recommend some extra materials to students, but the problem is that students don't follow teachers' suggestions. One teacher said that students' Chinese cultural deposits are poor, let alone the English expression of Chinese culture. In terms of promoting students' ability of expressing Chinese culture, the first step is to increase the input, but in fact there isn't enough time, if too much time is spent on Chinese culture teaching, definitely it will influence the normal class schedule.

\section{Reasons for “Chinese Cultural Aphasia”}

The reasons of "Chinese Cultural Aphasia” are to be analyzed from three perspectives, including students, teachers and the textbook.

In terms of students, they can realize the importance of intercultural communication ability, but due to the heavy study tasks or other reasons, they don't spend extra time to know about the English expressions of Chinese culture on their own initiative, and they pay more attention to the exam scores. Although sometimes teachers 
assign some materials for them to learn, they don't care about, because it doesn't influence their scores of final exam at all.

In terms of teachers, they lack consciousness of Chinese culture. English is a main course of senior high school learning, and the English scores have a great influence on students' entrance of universities. But in NEMT the check of Chinese culture takes up only a little, so in the process of English teaching, high school teachers often emphasize the input of target language but neglect the output of native culture. Firstly, the teaching idea is not correct, teachers often request their students to master the culture and customs of foreign countries, although sometimes assign some materials related to Chinese culture for students, they don't take any measures to check students' mastery degree, which causes the ignorance of students. Secondly, the culture teaching method is single, due to large amount of vocabularies and passage length, teachers only present the knowledge without interacting with students, which can not draw the interest of students. Thirdly, when teachers assign exam to check students' study situation, they lack the test of cultural content.

In term of the textbook, the proportion of Chinese culture content is too little, and it doesn't provide enough expressions or vocabularies related to Chinese culture. The content is so flexible that it is very difficult to use when adding Chinese culture content into English teaching.

\section{Proposals of Solving the Problem}

\section{From Perspective of Students}

Students are the learning subjects, and they should take their own initiative to pay attention to the learning of some expressions about Chinese culture. Here are some suggestions for students: (1) Participate in classroom teaching actively and cooperate with teachers by following teachers' mind and take creative thinking. After class carefully finish the tasks that teachers assign and think over what teachers have said in class. (2) Search on the internet or watch films about Chinese culture that they are interested in. Interest is the best teacher. Although the time is not enough, students' accumulation plays an important part in English learning. (3) Don’t be scared of communicating with others in English. Practice makes perfect. The purpose of language learning is to communicate, and cooperative learning is an effective way to practice communication which is helpful to increase students' self-confidence. So students can set up interest groups to introduce Chinese culture to each other.

\section{From Perspectives of Teachers}

Teachers should develop dual-cultural quality. English teachers are the direct initiator and their understanding of double culture has a great influence on English teaching. High school English teachers should accumulate more knowledge about double culture, and know more about culture of both target language and native language by reading newspapers or magazines. Therefore, when teaching Chinese culture, teachers can introduce it from the appearance to the inner essence, and inspire students' divergent thinking and innovation besides infusing knowledge. Detailed proposals for teachers are in the following:

Change attitude to English teaching. Teachers should guide students to treat British and American culture and Chinese culture equally. Although the result of NEMT is very important, the language competence is also crucial for students' development in the future. Teachers should take a long view, and increase culture teaching appropriately instead of neglecting the input of Chinese culture. In teaching content, add more 
expressions related to Chinese culture in English, such as some expressions of daily food, festivals, the ancient famous works and so on.

Change the teaching methods. Teachers should make full use of textbooks, and deepen students' understanding of the contents of what have been learned by introducing the background knowledge. When teaching foreign culture, teachers can use the contrastive method. The contrastive approach to English teaching is an important device in intercultural teaching. Through the contrast between Chinese culture and foreign culture, it can develop students' interest to English learning and deepen their understanding of both target language and native language culture. Robinson (1985) once said that how people perceive other people is influenced by the degree of similarity perceived. By analyzing the similarities and differences of two languages, students can increase their cultural awareness. What's more, teachers should change the ways of presenting, that is to say, teachers can create more opportunities for students to practice, such as dialogue or role play by assigning a topic.

Use the textbooks neatly. Since the proportion of Chinese culture in textbooks is very little, it is a great challenge for teachers to teach more about Chinese culture. When introducing culture knowledge, teachers should combine the textbooks and extra materials, at the same time, break the boundaries of different subjects, and integrate Chinese culture knowledge from all subjects into English teaching.

Increase the check of expressions related to Chinese culture. Evaluation is an important part in English learning for both teachers and students. It can make teachers acquire the feedback of the students' English study (Richards, 2000). A good score of the test has a positive effect on Students' English learning. If teachers can put the Chinese culture content into examination, it must attract students' attention and learn it carefully.

\section{From Perspectives of the Textbook}

The proportion of Chinese culture in textbooks should be increased. Textbooks are always batons for teachers to teach and the important source for students to acquire culture knowledge. Therefore, the textbooks should be adjusted appropriately and increase the English materials that can reflect Chinese culture. In English teaching of each module, import and strengthen Chinese culture teaching systematically. Besides, some wonderful passages and listening materials should be added, which can increase the information input. The textbooks should balance the input of the target language and native language culture, which can promote students' respect and approval of Chinese culture and make students better understand and spread the glorious Chinese culture.

\section{Conclusion}

"Chinese Cultural Aphasia" does exist in senior high school English teaching, By analyzing the questionnaire and test paper for students, as well as the interview for teachers, the reasons to cuase "Chinese Cultural Aphasis" can be analyzed from three aspects, including students, teachers and the text book. Accordingly, some proposals are put forward in this paper: (1) Students should pay attention to English expressions of Chinese culture; (2) Teachers should develop double culture ability, change their attitude to English teaching, change the teaching method, use the textbooks neatly, increase the check of expressions related to Chinese culture; (3) Increase the proportion of Chinese culture in the textbooks. 


\section{References}

CONG, C. (2000). “Aphasia of Chinese culture”: The limitation of English teaching. Guangming Daily.

LIU, C. J. (2003). Lose and recurrence of native culture in Foreign language teaching. Modern Educaiton Management, (12), 74-75.

Richard, J. C. (2000). Curriculum development in language teaching. New York: Cambridge University Press.

Robinson, G. L. N. (1985). Cross-cultural understanding: Process and approaches for foreign language, English as a second language and bilingual education. New York: Pergamon Press.

XING, L. H., \& WEI, Y. Z. (2012). Chinese Cultural Aphasia of Senior High School English teaching. Science and Technology Information, (33), 294.

YAN, Y. L. (2002). Awareness of native culture under globalization. Journal of Sichuan International Studies University, (18), 159-160.

ZHANG, L. Y. (2009). Chinese culture’s “Aphasia” phenomenon in Middle School's English teaching. Chongqing: Southwest University.

ZHANG, W. M., \& ZHU, H. M. (2002). Incorporating Chinese culture into college English teaching. Journal of Research on Education Tsinghua University, (S1), 35-40.

ZHAO, H. (2017). Research on the phenomenon of Chinese Culture Aphasis in Senior High School English teaching. Hebei: Hebei Normal University. 